\title{
DESENVOLVIMENTO DE UM SISTEMA DE AUTOMAÇÃO DE NÍVEIS DIGITAIS
}

Development of an Automation system of digital levels

\author{
SILVIO HENRIQUE DELLESPOSTE ANDOLFATO ${ }^{1}$ \\ PEDRO LUIS FAGGION ${ }^{2}$ \\ ${ }^{1}$ Universidade Tecnológica Federal do Paraná - UTFPR \\ Campus Pato Branco - Via do Conhecimento - km 01 \\ CEP 85.503-390 - Pato Branco - PR \\ ${ }^{2}$ Universidade Federal do Paraná - UFPR \\ Setor de Ciências da Terra - SCT \\ Centro Politécnico - Jardim das Américas \\ Caixa Postal 19001 - CEP- 85.531-990 - Curitiba PR \\ e-mail: andolfato@utfpr.edu.br ; faggion@ufpr.br
}

\begin{abstract}
RESUMO
Este trabalho apresenta o desenvolvimento de um Sistema de Automação para Níveis Digitais - SAND, composto por uma plataforma que aloja os motores de passo e os sistemas de engrenagem para realizar o monitoramento de estruturas de obras civis, em tempo real, de forma automática, ou seja, sem a necessidade de um técnico para operar o nível. Esta plataforma é controlada por uma placa microcontroladora, que permite o movimento horizontal do nível geodésico digital, sem a interferência do observador. Além disso, esta plataforma acomoda um motor que é utilizado para realizar a focalização da imagem das miras verticais que são instaladas junto ao objeto que se deseja realizar o monitoramento. Utilizando técnicas do nivelamento geométrico, o SAND realiza as leituras da mira com códigos de barra, visando à determinação dos desníveis entre os pontos de interesse e com isso determinar possíveis deslocamentos da estrutura. Os resultados obtidos e apresentados demonstram a viabilidade da aplicação da metodologia proposta.
\end{abstract}

Palavras-chave: Nível Digital; Sistema de Automação; Monitoramento de Estruturas. 


\begin{abstract}
This paper presents the development of an Automation System for Digital Levels SAND, consisting of a platform that houses the stepper motors and gear systems to perform the monitoring of civil structures in real time, automatically, i.e., without the need for a technician to operate the level. This platform is controlled by a microcontroller board, which allows horizontal movement of geodesic level digital, without interference from the observer. In addition, this platform accommodates an engine that is used for focusing the image of the vertical sights that are installed next to the object you want to perform the monitoring. Using leveling techniques, the SAND takes readings of sight with bar codes, to determine the gaps between the points of interest and thereby determine possible shifts in the structure. The results presented and demonstrate the feasibility of the proposed methodology.
\end{abstract}

Keywords: Level Digital; Automation System; Monitoring of Structures.

\title{
1. INTRODUÇÃO
}

O monitoramento preciso de recalque de grandes estruturas é possível de ser realizado utilizando nivelamento geométrico. Em muitas estruturas é necessário o acompanhamento do deslocamento ao longo do tempo e sem interrupções. Nestas circunstâncias o desgaste do operador é inevitável podendo causar inconsistência nos resultados obtidos.

Buscando disponibilizar uma ferramenta para atender esta necessidade, desenvolveu-se um sistema de automação de níveis geodésicos digitais, que dispensa o operador através da automação do movimento horizontal, do sistema de focalização do nível e armazenamento dos dados.

Atualmente, entende-se por automação qualquer sistema, apoiado em computadores que substitua o trabalho humano e que vise a soluções rápidas e econômicas para atingir os complexos objetivos das indústrias e dos serviços (MORAES; CASTRUCCI, 2001, p.15).

Segundo Veiga et al (2006), do ponto de vista prático, por automação entende-se um sistema automático pelos quais os mecanismos controlam seu funcionamento, dispensando, quase por completo, a interferência do ser humano. O autor também conclui, que independente do grau de automatização, o objetivo final é comum, que a intervenção do operador seja a mínima possível, da coleta dos dados até a representação final da área levantada.

Segundo Cintra (1993) o processo de automação topográfica iniciou-se na década de 1960 com a construção dos teodolitos-taquímetros, desenvolvido pelas empresas FENNEL e KERN, que gravava as medidas em um filme fotográfico de $35 \mathrm{~mm}$. Este autor trata, ainda, das automações dos trabalhos de campo e de escritório, onde são apresentados os processos tradicionais e eletrônicos, equipamentos topográficos eletrônicos, automação dos cálculos e de projetos. 
Sistemas de automação e coleta de dados podem ser observados em grandes obras de engenharia, onde os estudos realizados verificam a praticidade e os bons resultados obtidos com esta técnica, que caracteriza como a solução mais prática e econômica ao uso de estações totais robotizadas em um sistema completo de automação na obtenção de medidas (LUTES, et al, 2001). Com o programa apropriado, os dados podem ser coletados, processados automaticamente e transferidos para os locais de análise gerando uma redução de trabalho e custo necessários para a coleta dos mesmos. (NADAL, 2008).

Em trabalhos de nivelamento geométrico, realizados pela equipe de pesquisadores da UFPR, vinculados ao Projeto Integração da Auscultação Geodésica com a Instrumentação de Controle e Segurança da Usina de Salto Caxias, utilizando níveis digitais, chegou-se a precisão de $0,5 \mathrm{~mm} . \sqrt{k}$, mostrando assim, a eficácia da utilização desses equipamentos em nivelamentos de alta precisão.

Apesar do GPS e outras técnicas alternativas para determinação de altitudes, o nivelamento clássico tem mantido sua importância, especialmente no domínio de nivelamentos de primeira e segunda ordem, de determinações de altitudes precisas e determinações de alturas em túneis. (SCHNEIDER; DIXON, 2002).

A idéia de desenvolver um sistema automatizado para a determinação de desníveis empregando-se níveis digitais tem como um dos itens a ser trabalhado o entendimento de como é realizada a leitura do código de barras gravado na mira, para que seja desenvolvido um dispositivo para realizar as leituras automaticamente.

\section{METODOLOGIA}

\subsection{Desenvolvimento do Sistema de Automação do Nível Digital - SAND}

Além do nível digital (instrumento) propriamente dito, para entendimento do SAND, têm-se os seguintes componentes, a saber:

a- Miras com código de barras (alvos construídos);

b-Hardware: motores de passo, dispositivo de adaptação dos motores, driver de potência e placa microcontroladora;

c- Software: programa para movimentação do nível digital.

\subsubsection{Miras com Código de Barras (Alvos Construídos)}

Para este trabalho foi realizado uma checagem das informações técnicas referente à mira com códigos de barras, sendo realizada uma análise da mira de ínvar da Leica, modelo GWCL92, n ${ }^{\circ} 9117$ (LEICA, 2004), onde foram medidas as espessuras dos elementos de códigos pretos e brancos, realizadas no interferômetro a laser (Figura 1), do Laboratório de Aferição e Instrumentação Geodésica - LAIG, na Universidade Federal do Paraná - UFPR. 
Figura 1 - Interferômetro a laser utilizado.

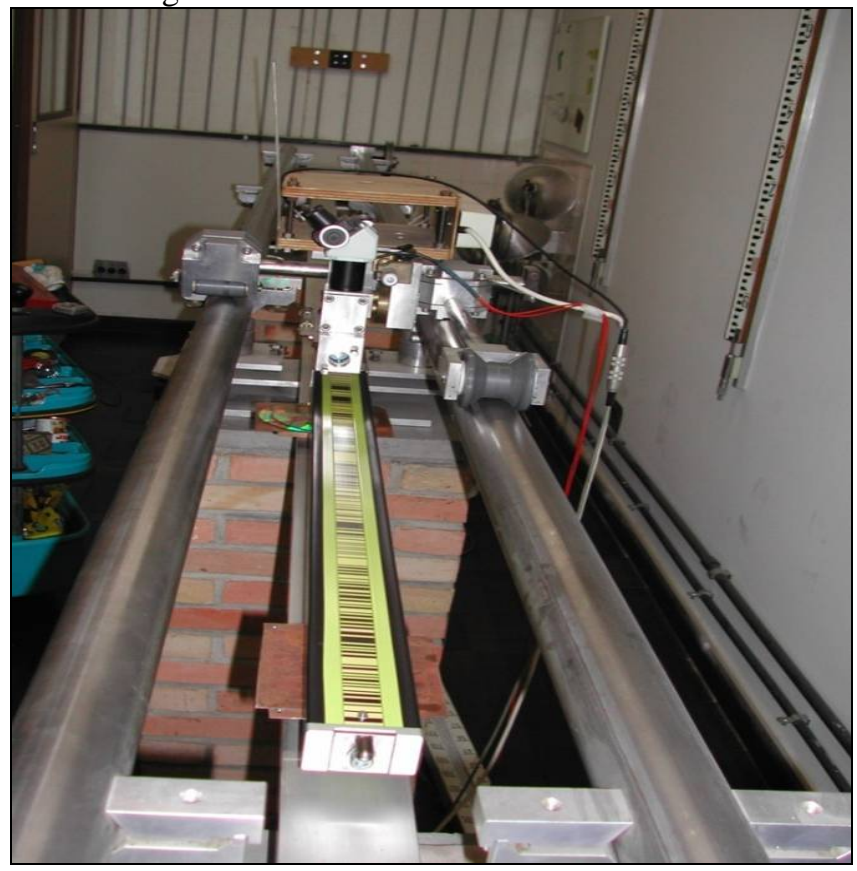

Primeiramente, partiu-se para a análise do código, verificando com auxílio de um paquímetro, as espessuras de cada elemento do mesmo, obtendo-se a seqüência entre os códigos pretos e brancos, tendo em cada espessura um múltiplo de 2,025 $\mathrm{mm}$. Adotou-se a nomenclatura de "P" para o elemento de código preto e "B" para o branco, seguido do múltiplo "M” em questão. Como exemplo, tem-se:

$\mathrm{PM}=$ elemento de Código Preto $\mathrm{x}$ Múltiplo de 2,025 mm (exemplo: P3 = Preto com espessura de 3x2,025, totalizando 6,075 mm);

$\mathrm{BM}=$ elemento de Código Branco $\mathrm{x}$ Múltiplo de 2,025 mm (exemplo: $\mathrm{B} 2$ = Branco com espessura de 2x2,025, totalizando 4,050 mm).

Assim, com os elementos do código de barra determinados, construiu-se os alvos, através da plotagem em papel dos mesmos, sendo posteriormente plastificados. A Figura 2 mostra a comparação da mira original com o alvo confeccionado. 
Figura 2 - Detalhe da comparação entre a mira original e o alvo confeccionado.

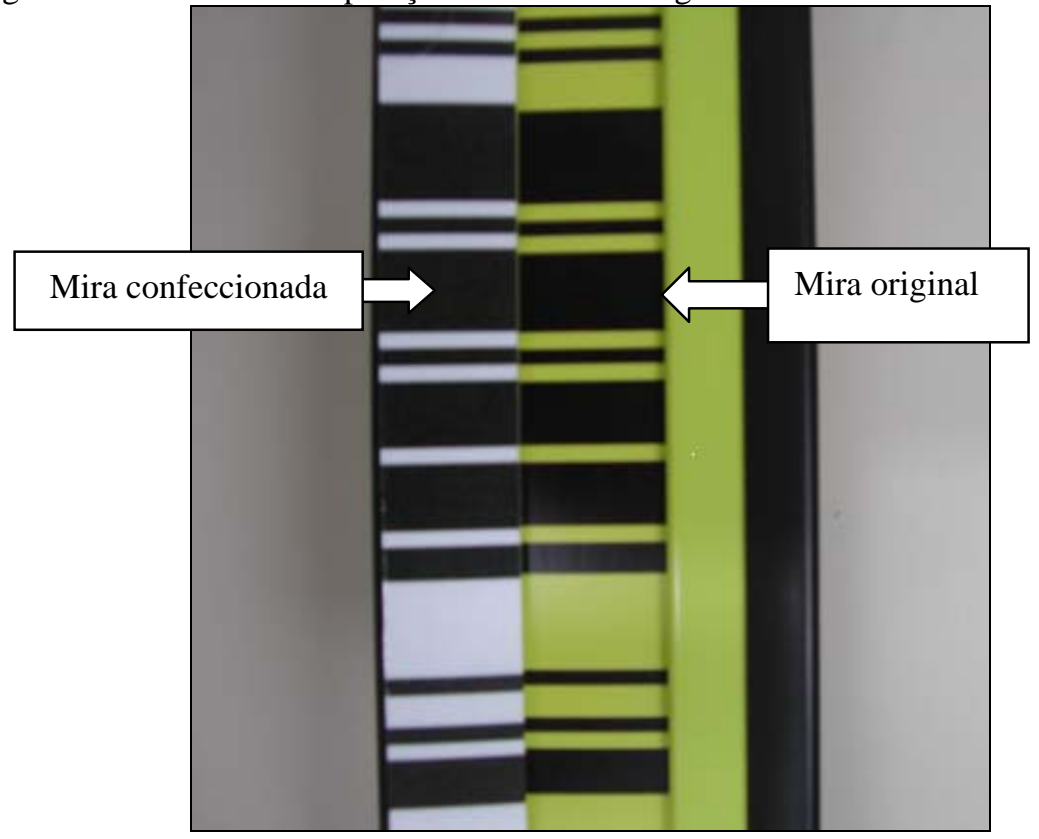

\subsubsection{Hardware}

O hardware estabelecido para o SAND é composto por 4 partes básicas: motores de passo, Dispositivo de Adaptação dos Motores de Passo - DAMP, driver de potência e a Placa Microcontrolada para Comando dos Motores de Passo PMCMP.

\subsubsection{Motor de Passo}

Um motor de passo é um dispositivo digital. Isto quer dizer que ele se movimenta conforme recebe pulsos de tensão contínua numa determinada frequência. $\mathrm{O}$ motor de passo responde fielmente a cada pulso e esta é a principal característica dele. Ao receber o sinal, o motor faz um incremento rotativo que é chamado de passo (LEITE et al, 2003).

Neste trabalho utilizou-se dois motores de passo (Figura 3), um para o movimento horizontal do nível digital e outro para o movimento de focalização da imagem da mira, ambos do modelo AK39HY/12-1.8, com 200 passos $\left(1,8^{\circ}\right)$ para o ajuste da focagem e o AK56H8/5-1.8 para o giro horizontal do nível, adquiridos da 
Andofato, S. H. D. e Faggion, P. L.

empresa Akiyama Tecnologia em Componentes Eletrônicos Ltda. AKIYAMA, 2009b; AKIYAMA, 2009c).

Figura 3 - Motores de passo utilizados.

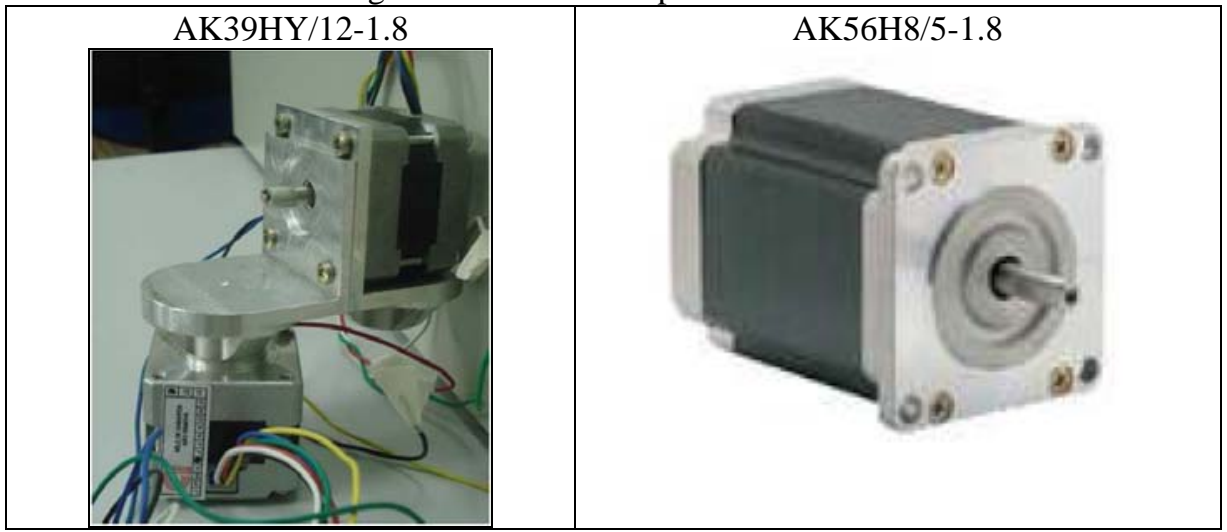

\subsubsection{Dispositivo de Adaptação dos Motores de Passo - DAMP}

Para a adaptação dos motores utilizados ao nível digital, de forma que esta adaptação fosse realizada externamente ao instrumento, foi projetado e construído um dispositivo onde os motores fossem instalados para que pudessem executarem as suas funções, quer sejam do ajuste de focagem e do movimento horizontal do instrumento. A Figura 4 mostra o projeto e o DAMP construído.

Figura 4 - Dispositivo de Adaptação dos Motores de Passo.

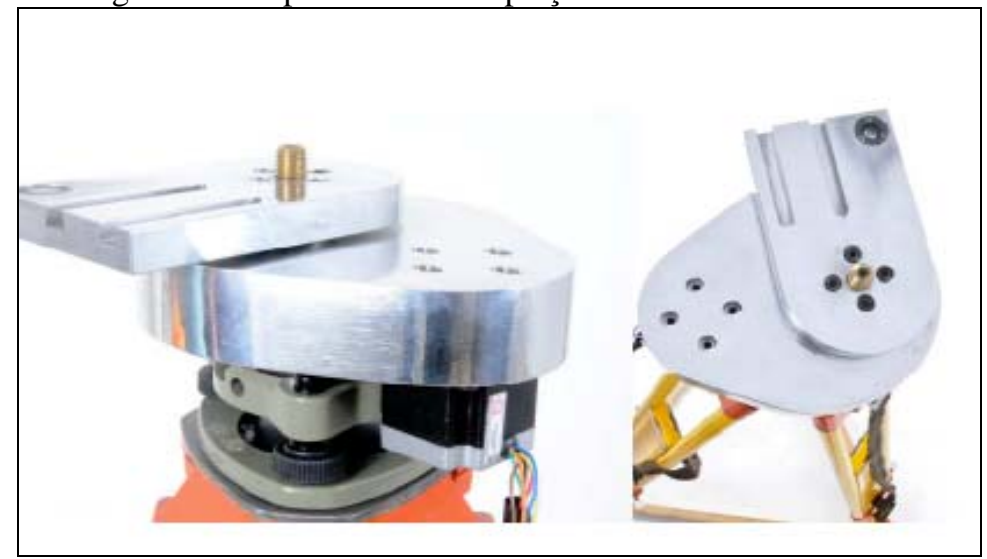

Bol. Ciênc. Geod., sec. Artigos, Curitiba, v. 17, nº 1, p.188-199, abr-jun, 2011. 


\subsubsection{Driver de Potência}

O driver de potência modelo AKDMP5-1.7A (Figura 5) foi adquirido da mesma empresa fornecedora dos motores de passo, Akiyama Tecnologia em Componentes Eletrônicos Ltda. Este driver apresenta algumas chaves de seleção onde podem ser selecionados as divisões do passo em 1:2, 1:5, 1:10, 1:20 e 1:40 , sendo correspondidos em ângulos $\left({ }^{\circ}\right.$ ) de 0.9, 0.36, 0.18, 0.09 e 0.045, respectivamente. (AKIYAMA, 2009a).

Figura 5 - Driver de potência.

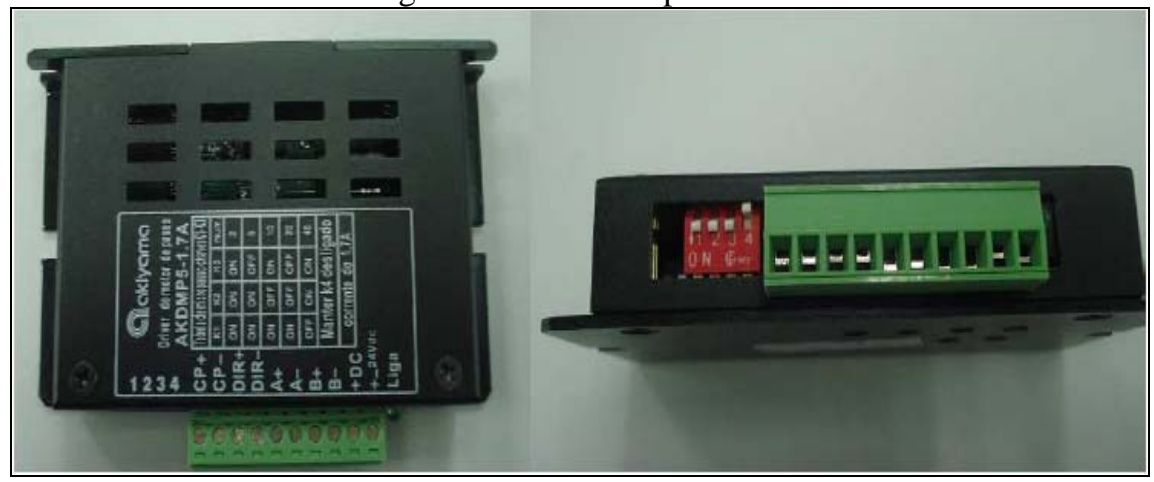

\subsubsection{Placa Microcontroldaora para Comandos dos Motores de Passo - PMCMP}

O sistema de controle, acionamentos e comunicação serial é proveniente de uma placa eletrônica, conhecida popularmente como Roboduino 1.0; a qual é proveniente de um projeto open source (ARDUINO, 2010a). Seus principais componentes e características são:

- Microcontrolador ATMEGA168 ou ATMEGA328;

- Circuito de comunicação com micro-computador ou laptop via USB-Serial;

- Fonte interna e externa com reguladores de tensões.

O microcontrolador envia sinais em duas entradas da placa de potência. Na primeira é enviado pulsos elétricos numa determinada frequência controlando assim a quantidade de passos e a velocidade do motor. Na segunda entrada é enviado um sinal comandando o sentido de giro do motor: nível alto (5V) o motor gira no sentido horário e nível baixo (0V) o motor gira no sentido anti-horário.

$\mathrm{O}$ driver de potência recebe os sinais do microcontrolador e recebe de uma fonte de energia, uma tensão de 12 a $24 \mathrm{~V}$ e aciona suas saídas, mandando energia para as bobinas do motor de passo. 
A programação do microcontrolador foi elaborada no software Arduino Alpha V. 0018, o qual também é open source e pode ser localizado facilmente na internet (ARDUINO, 2010b).

Neste programa, o operador faz a marcação da posição das miras colocadas em pontos de interesse, gravando a quantidade de passos do motor necessários para a movimentação entre os pontos desejados, tanto para o giro horizontal quanto para o ajuste do foco, podendo selecionar a opção de realizar " $n$ " repetições de leituras com um intervalo de tempo entre elas, que pode variar de 1 a 60 minutos, ou seja, caso se coloque 2 repetições e 15 minutos, o sistema realizará as duas medições nos pontos gravados e após 15 minutos realizará outras duas medições nestes mesmos pontos, e assim se repete sucessivamente.

\section{TESTES REALIZADOS}

\subsection{Testes com as Miras Confeccionadas}

De posse das miras com códigos de barra confeccionados, realizou-se uma calibração da mesma, com o uso do interferômetro a laser, obtendo-se o resultado apresentado na Tabela 1, com o objetivo de verificar se o nível digital conseguia realizar a leitura das mesmas.

Tabela 1 - Diferenças encontradas da mira original com a mira confeccionada (10 ${ }^{-3}$ $\mathrm{mm})$.

\begin{tabular}{c|c|c|c|c}
\hline código & padrão & soma & leitura & diferença \\
\hline inicio & 0 & 0 & 0 & 0 \\
\hline B5 & 10125 & 10125 & 10120 & 5 \\
\hline P3 & 6075 & 16200 & 16203 & -3 \\
\hline B3 & 6075 & 22275 & 22279 & -4 \\
\hline P1 & 2025 & 24300 & 24304 & -4 \\
\hline B3 & 6075 & 30375 & 30369 & 6 \\
\hline P1 & 2025 & 32400 & 32394 & 6 \\
\hline B1 & 2025 & 34425 & 34421 & 4 \\
\hline P3 & 6075 & 40500 & 40494 & 6 \\
\hline B1 & 2025 & 42525 & 42523 & 2 \\
\hline P2 & 4050 & 46575 & 46569 & 6 \\
\hline B1 & 2025 & 48600 & 48601 & -1 \\
\hline P1 & 2025 & 50625 & 50622 & 3 \\
\hline B2 & 4050 & 54675 & 54669 & 6 \\
\hline P1 & 2025 & 56700 & 56698 & 2 \\
\hline B1 & 2025 & 58725 & 58723 & 2 \\
\hline P1 & 2025 & 60750 & 60742 & 8 \\
\hline B1 & 2025 & 62775 & 62774 & 1 \\
\hline P2 & 4050 & 66825 & 66822 & 3 \\
\hline B1 & 2025 & 68850 & 68852 & -2 \\
\hline P1 & 2025 & 70875 & 70877 & -2 \\
\hline & & & &
\end{tabular}

\begin{tabular}{c|c|c|c|c}
\hline código & padrão & soma & leitura & diferença \\
\hline B1 & 2025 & 194400 & 194391 & 9 \\
\hline P3 & 6075 & 200475 & 200475 & 0 \\
\hline B1 & 2025 & 202500 & 202493 & 7 \\
\hline P2 & 4050 & 206550 & 206555 & -5 \\
\hline B2 & 4050 & 210600 & 210594 & 6 \\
\hline P3 & 6075 & 216675 & 216670 & 5 \\
\hline B1 & 2025 & 218700 & 218700 & 0 \\
\hline P2 & 4050 & 222750 & 222749 & 1 \\
\hline B1 & 2025 & 224775 & 224773 & 2 \\
\hline P1 & 2025 & 226800 & 226799 & 1 \\
\hline P2 & 4050 & 230850 & 230841 & 9 \\
\hline P1 & 2025 & 232875 & 232874 & 1 \\
\hline B3 & 6075 & 238950 & 238947 & 3 \\
\hline P2 & 4050 & 243000 & 243003 & -3 \\
\hline B1 & 2025 & 245025 & 245019 & 6 \\
\hline P2 & 4050 & 249075 & 249074 & 1 \\
\hline B1 & 2025 & 251100 & 251101 & -1 \\
\hline P2 & 4050 & 255150 & 255153 & -3 \\
\hline B1 & 2025 & 257175 & 257170 & 5 \\
\hline P1 & 2025 & 259200 & 259201 & -1 \\
\hline B7 & 14175 & 273375 & 273362 & 13 \\
\hline & & & &
\end{tabular}


As diferenças encontradas ficaram na ordem do micrômetro $\left(10^{-3} \mathrm{~mm}\right)$, devido ao processo de impressão da mira, que fora feito em dois materiais para testes, em papel sulfite e em plástico tipo PVC sendo que foram utilizadas as miras em PVC devido a sua facilidade de uso.

Verifica-se que a maior diferença encontrada entre a mira original e a mira confeccionada foi de $0,013 \mathrm{~mm}$, sendo que este resultado não interfere nas leituras e consequentemente nas diferenças de nível.

Para a verificação das miras confeccionadas, realizou-se um experimento com a leitura dessas miras, adotando-se a visada Ré (fixa) realizada com a mira original e as visadas Vante com as miras confeccionadas, colocadas em dois pontos, chamados aqui por Vante 1 e Vante 2, obtendo-se o desnível entre os pontos Ré e Vante $(\Delta \mathrm{H} 1$ e $\Delta \mathrm{H} 2)$.

Apresentam-se na Tabela 2 os valores das leituras realizadas e o desnível calculado:

Verifica-se que nos resultados realizados com as leituras das miras, tanto a original quanto as confeccionadas, apresentaram resultados satisfatórios, uma vez que as diferenças entre as medições ficaram na ordem do centésimo do milímetro $\left(10^{-5} \mathrm{~mm}\right)$, demonstrando que as miras confeccionadas apresentam-se aptas para sua utilização.

Tabela 2 - Desníveis calculados utilizando as miras confeccionadas em Vante 1 e Vante 2.

\begin{tabular}{c|c|c|c|c|c}
\hline $\begin{array}{c}\text { Mediçã } \\
\text { o }\end{array}$ & $\begin{array}{c}\text { Leitura Ré } \\
(\mathrm{m})(\mathrm{mira} \\
\text { original) }\end{array}$ & $\begin{array}{c}\text { Leitura } \\
\text { Vante 1 } \\
(\mathrm{m})\end{array}$ & $\begin{array}{c}\Delta \mathrm{H} 1 \\
(\mathrm{~m})(\mathrm{Ré}- \\
\text { Vante1) }\end{array}$ & $\begin{array}{c}\text { Leitura } \\
\text { Vante 2 } \\
(\mathrm{m})\end{array}$ & $\begin{array}{c}\Delta \mathrm{H} 2(\mathrm{~m}) \\
(\text { Ré }- \\
\text { Vante2) }\end{array}$ \\
\hline 1 & 0,53680 & 0,75842 & $-0,22162$ & 0,47154 & 0,06526 \\
\hline 2 & 0,53681 & 0,75843 & $-0,22162$ & 0,47154 & 0,06527 \\
\hline 3 & 0,53682 & 0,75843 & $-0,22161$ & 0,47155 & 0,06527 \\
\hline 4 & 0,53681 & 0,75842 & $-0,22161$ & 0,47155 & 0,06526 \\
\hline 5 & 0,53680 & 0,75842 & $-0,22162$ & 0,47155 & 0,06525 \\
\hline 6 & 0,53679 & 0,75840 & $-0,22161$ & 0,47153 & 0,06526 \\
\hline 7 & 0,53679 & 0,75840 & $-0,22161$ & 0,47152 & 0,06527 \\
\hline médias & 0,5368028 & 0,7584171 & $-0,2216143$ & 0,4715400 & 0,0652628 \\
\hline
\end{tabular}

\subsection{Testes com o SAND}

Com a utilização prática do SAND, foram realizados diversos testes de funcionamento do sistema, verificando a sua funcionalidade e repetibilidade nas obtenções das leituras das miras confeccionadas, colocadas em dois pontos, chamados de 1 e 2.

A Figura 6 mostra um segmento do arquivo gerado em um dos testes realizados com o SAND. Considerando que este arquivo é extenso (várias linhas), verifica-se que o sistema teve uma duração de $7 \mathrm{~h}$ 45min 41s, sendo realizadas duas repetições de leituras com um minuto de intervalo entre as repetições. 
Figura 6 - Detalhe do arquivo gerado pelo SAND.

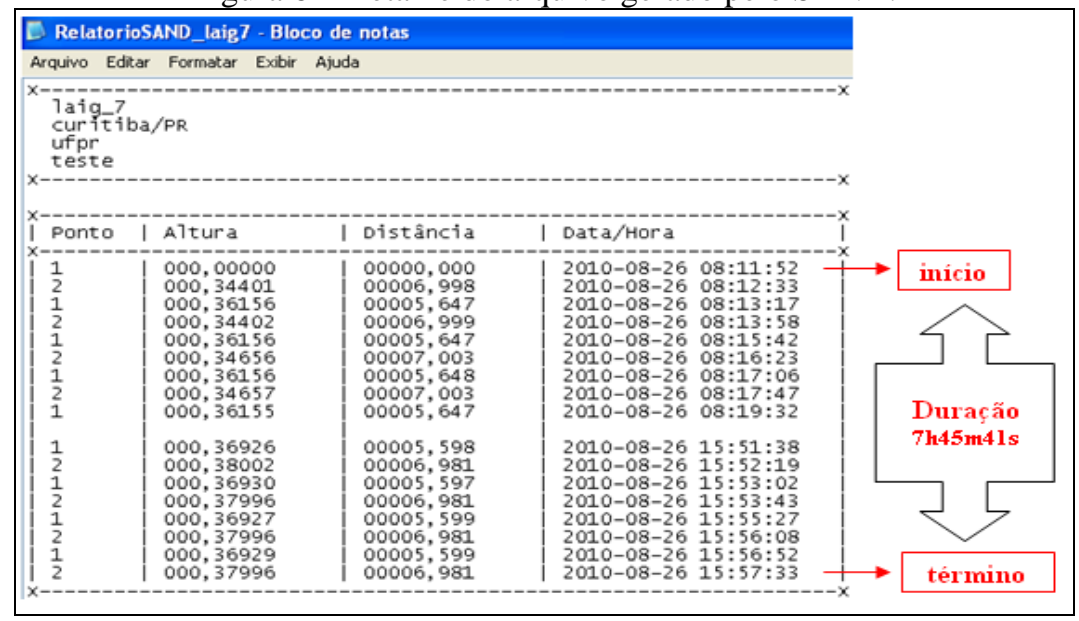

Um segundo teste realizado verificou a diferença de leituras encontradas (desníveis entre as miras colocadas nos pontos 2 e 1 ), onde a mira do ponto 1 permaneceu fixa e a mira do ponto 2 fora deslocada de forma aleatória (simulandose um possível deslocamento do ponto), obtendo-se as diferenças mostradas na Figura 7. Nota-se neste teste que o SAND foi capaz de obter as leituras, ao longo de um período de 5 h 51min 02s.

Figura 7 - Diferenças de alturas encontradas.

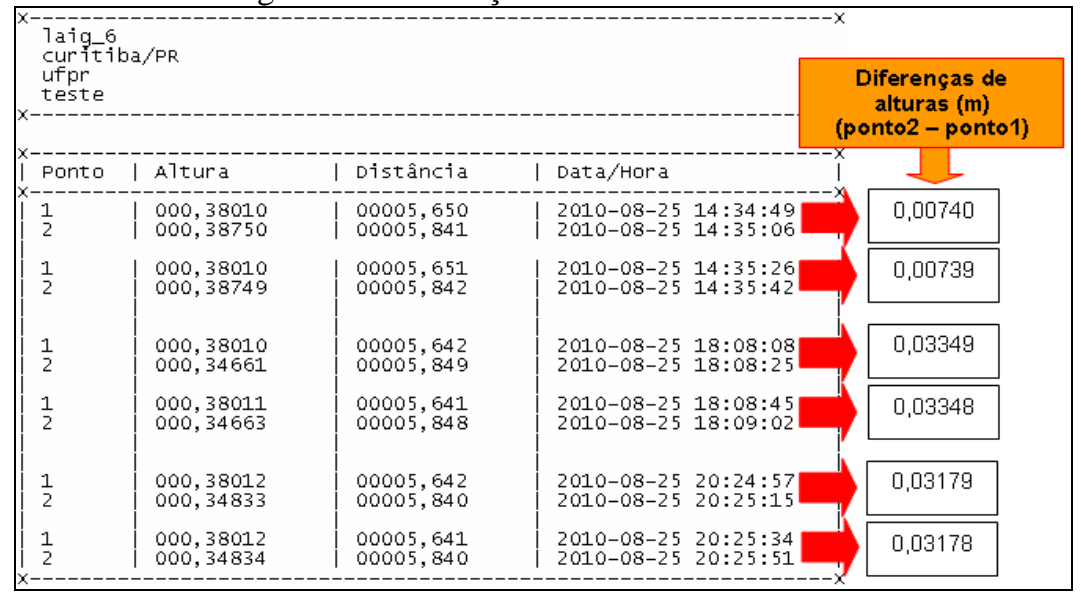

Bol. Ciênc. Geod., sec. Artigos, Curitiba, v. 17, nº 1, p.188-199, abr-jun, 2011. 


\section{CONCLUSÃO}

O sistema mostrou-se adequado para a obtenção das leituras das miras colocadas em pontos de interesse, realizando de forma contínua, a obtenção das leituras das miras, podendo ser de minuto em minuto, verificando possíveis deslocamentos que possam ocorrer nos pontos monitorados.

A automação de níveis digitais, desenvolvida neste trabalho, se mostrou eficiente para realizar o monitoramento contínuo de recalque de estruturas.

No primeiro teste realizado, o SAND ficou coletando dados durante $7 \mathrm{~h} 45 \mathrm{~min}$ 41s, com um intervalo entre séries de 1 minuto. Num trabalho de monitoramento com estas características seria impossível de ser desenvolvido por um técnico operando o nível de forma tradicional, demonstrando assim que este sistema é viável e prático para a obtenção das leituras das miras.

Já no segundo teste, durante um período de 5 h 51 min 02s, a mira $n^{\circ} 2$ (ponto 2) foi deslocada de forma aleatória por 2 vezes e a mira $n^{0} 1$ ficou imóvel (simulando-se um deslocamento no ponto 2). No início a leitura média no ponto 2 estava em torno de $0,38750 \mathrm{~m}$. Após o primeiro deslocamento da mira sua leitura média passou a ser de $0,34661 \mathrm{~m}$ e após o segundo deslocamento passou a 0,34833 $\mathrm{m}$.

Percebe-se que neste teste que o SAND é capaz de obter leituras após um possível deslocamento, determinando-se assim o desnível entre os pontos de controle juntamente com o horário em que este deslocamento ocorreu.

Os resultados obtidos mostram que o SAND pode ser empregado no monitoramento de obras de engenharia, tais como: usinas hidrelétricas, pontes, edificações urbanas, entre outras, buscando-se o aumento da produtividade, coletando-se dados de forma contínua e durante longos períodos, subsidiando a tomada de decisão, quando detectados deslocamentos absolutos ou relativos entre os pontos de controle.

O custo de fabricação do sistema de automação de níveis digitais (SAND) é baixo considerando os benefícios que o sistema traz na execução do monitoramento de uma obra durante e após sua construção.

\section{REFERÊNCIAS BIBLIOGRÁFICAS}

AKIYAMA. Manual do usuário - AKDMP5-1.7A - Driver motor de passo de 2 fases. Disponível em: http://www.motores.akiyama.com.br/pdf/Manual\% 20\%20AKDMP5-1.7A.pdf. Acesso em: 25 de ago. de 2009a.

AKIYAMA. Motor de passo AK39H/12-1.8 - datasheet. Disponível em: http://www.akiyama.com.br/site/mercados-e-solucoes.php?id=6\&id2=284 \&id4=26 . Acesso em: 25 de ago. de 2009b.

AKIYAMA. Motor de passo AK56H8/5-1.8 - datasheet. Disponível em: http://www.akiyama.com.br/site/mercados-e-solucoes.php?id=6\&id2=286 \&id4=26 . Acessado em 25 de agosto de 2009c. 
ARDUINO. Disponível em: http://arduino.cc/en/Main/Software. Acesso em: 10 jun. 2010a.

ARDUINO. Disponível em http://arduino.cc/en/Reference/HomePage. Acesso em: 10 jun. 2010b.

CINTRA. J. P. Automação da topografia: do campo ao projeto. 120p. Tese (Livre Docência) - Escola Politécnica. Universidade de São Paulo. São Paulo, 1993.

LEICA. DNA03/DNA10 - Manual do usuário. Versão 1.2 - Português. 2004.

LEITE, B. H. F. C.; LIMA, E. J. C; LEÃO, F. L.; PRESTES, R. F. Estudo do motor de passo e seu controle digital (2003). Disponível em: http://recreio.gta.ufrj.br/grad/01_1/motor/. Acesso em: 13 Fev. 2008.

LUTES, J.; CHRZANOWKI, A.; BASTIN, G.; WHITAKER, C. 'Dimons' programa for automatic data collection and automatic deformation analysis. The 10th FIG International Symposium on Deformation Measurements. 2001.

MORAES, C. C.; CASTRUCCI, P. L. Engenharia de automação industrial. Rio de Janeiro: LTC, 2001.

NADAL, M. A. D. Controle e operação remota de estações totais robotizadas voltado à auscultação geodésica. 132 f. Dissertação (Mestrado) Universidade Federal do Paraná, Setor de Ciências da Terra, Curso de PósGraduação em Ciências Geodésicas. Curitiba, 2008.

SCHNEIDER, F.; DIXON, D. The New Leica Digital Levels DNA03 and DNA10. In: FIG XXXII International Congress. Washington, D.C. USA, 2002.

VEIGA et al. O Uso de Poligonais de Precisão para o Monitoramento de Pontos em Galerias de Drenagem: A Experiência na Usina Hidrelétrica de Salto Caxias. In: Anais do III Simpósio sobre Instrumentação de Barragens, p. 287-295. Comitê Brasileiro de Barragens - CBDB. São Paulo-SP, 2006.

(Recebido em junho de 2010. Aceito em maio de 2011.) 